\title{
Rechazo de solicitudes de opinión consultiva por parte de la Corte Interamericana de Derechos Humanos
}

\author{
The Inter-American Court of Human Rights Rejection \\ of Requests for Advisory Opinions \\ ÁLVARO PAÚL ${ }^{1}$ \\ Pontificia Universidad Católica, Chile
}

RECEPCIÓN: 31/08/2016 • ACEPTACIÓN: 27/01/2017

RESUMEN: La Corte Interamericana de Derechos Humanos tiene una función consultiva muy amplia, tanto por los legitimados para solicitar una opinión como por los temas que puede tocar. No obstante esta amplitud, declina referirse a algunas solicitudes de opinión consultiva. Los motivos para hacerlo son variados, y han sido desarrollados por la Corte a través de su jurisprudencia. Este trabajo sistematiza tales dictámenes y analiza la extensión y conveniencia de los criterios elaborados por la Corte.

PALABRAS CLAVE: Corte Interamericana de Derechos Humanos - Opiniones Consultivas - Competencia.

ABSTRACT: The Inter-American Court of Human Rights has a broad advisory jurisdiction, both because of the many entities entitled to request an opinion, and because of the range of matters that the Court may address. Notwithstanding this

1. Profesor de Derecho Internacional y Derechos Humanos en la Pontificia Universidad Católica de Chile (PUCCh). Doctor en Derecho de Trinity CollegeDublin, Máster en Derecho por la U. de Oxford, Licenciado por la U. de los Andes. Correo electrónico: alvaro.paul@uc.cl. Este trabajo fue elaborado sobre la base del aporte del autor para la opinión de la Facultad de Derecho de la PUCCh sobre la reciente solicitud de opinión consultiva de Costa Rica. 
breadth, the Court decides not to answer some requests. The reasons for doing so are varied, and have been developed by the Court through its case law. This paper systematizes the decisions declining to give an opinion, and analyzes the scope and convenience of the Court's criteria for doing so.

KEY WORDS: Inter-American Court of Human Rights - Advisory Opinions - Competence.

\section{Introducción}

Después de siete años sin hacerlo, la Corte Interamericana de Derechos Humanos rechazó pronunciarse sobre una solicitud de opinión consultiva ${ }^{2}$. Hasta el momento, la Corte se ha negado a pronunciar una opinión en solo cinco asuntos. La Convención Americana de Derechos Humanos $(\mathrm{CADH})$ no desarrolla la posibilidad de que la Corte rehúse dar su opinión cuando ello le sea solicitado, sino que solo afirma, respecto de ciertas consultas específicas -las referidas a la compatibilidad entre leyes nacionales y los tratados de derechos humanos-, que la Corte "podrá” dar su opinión ${ }^{3}$. Sin embargo, ello no ha impedido que la Corte considere que su competencia consultiva "es de naturaleza permisiva", y que tiene la facultad de apreciar si da o no respuesta a las consultas que recibe ${ }^{4}$. En atención a ello, ha presentado una serie de criterios según los cuales puede negarse a conocer de una opinión consultiva.

Es claro que la Corte puede negarse a emitir su opinión cuando la solicitud no cumple con los requisitos establecidos en la CADH. Sin embargo, podría ser discutible si puede limitar su tarea de emitir opiniones consultivas estableciendo criterios adicionales ${ }^{5}$. Esta nota no se pronunciará sobre este asunto, sino que parte de la base de que la Corte ya rechaza este tipo de solicitudes, lo que hace necesario examinar y sistematizar los casos en los que rehúsa emitir su opinión. Hasta el

2. Solicitud de Opinión Consultiva Presentada por el Secretario General de la Organización de los Estados Americanos (2016).

3. Art. 64 párr. 2 de la Convención Americana sobre Derechos Humanos. Disponible en: www.oas.org/dil/esp/tratados_B-32_Convencion_Americana_sobre_Derechos_Humanos.htm [fecha de consulta: 13 de octubre de 2016] [en adelante: CADH].

4. "Otros Tratados" Objeto de la Función Consultiva de la Corte (Art. 64 Convención Americana sobre Derechos Humanos) (1982).

5. Pasqualucci da algunos motivos para considerar adecuada la interpretación de la Corte. Pasqualucci (2014), p. 60. 
momento, ha sido escasa la doctrina que se ha referido a esta situación con cierto detalle $^{6}$, por lo que en esta nota buscamos complementar y actualizar dicha doctrina.

\section{Descripción de las solicitudes rechazadas}

\subsection{Solicitud sobre el sistema procesal penal costarricense}

La primera solicitud de opinión consultiva rechazada fue presentada por Costa Rica. Dicho Estado buscaba que la Corte resolviera ciertas dudas relevantes para efectos de reformar la normativa procesal penal costarricense y cumplir con lo dispuesto en el artículo 8.2.h de la $\mathrm{CADH}^{7}$. Al hacerlo, el Estado remitió a la Corte los artículos proyectados, de modo que ella pudiera dar su opinión de un modo más concreto ${ }^{8}$.

La Corte rechazó referirse a esta solicitud mediante una resolución del 6 de diciembre de 1991. Dicha decisión tiene una particularidad procesal, pues es la única resolución que, no obstante rechazar pronunciarse sobre el asunto, ha sido llamada oficialmente "opinión consultiva" (las demás han sido catalogadas como simples resoluciones).

Al declarar inadmisible esta solicitud, la Corte tuvo a la vista una presentación de Uruguay, según la cual podían ser objeto de consulta solo las disposiciones "que han recibido aprobación legislativa y promulgación ejecutiva" 10 . Tal Estado afirmó esto porque la CADH dispone solo en una ocasión que la Corte puede resolver consultas sobre normativa interna, y lo hace refiriéndose a "leyes internas", no a proyectos de ley ${ }^{11}$. Además, la Corte ya había definido el concepto de leyes en su opinión consultiva "La expresión Leyes", definiéndolas, grosso modo, como normas jurídicas de carácter general aprobadas por el Poder Legislativo ${ }^{12}$. Sin

6. V.gr., Pasqualucci (2014), pp. 59-66; Faúndez (2004), pp. 967-981; Burgorgue-Larsen y Úbeda (2011), pp. 89-90 y Hitters y Fappiano (2012), pp. 1884-1886.

7. Compatibilidad de un Proyecto de Ley con el Artículo 8.2.h. de la Convención Americana sobre Derechos Humanos (1991) párr. 3.

8. Ibid.

9. Compatibilidad de un Proyecto de Ley con el Artículo 8.2.h. de la Convención Americana sobre Derechos Humanos (1991).

10. Compatibilidad de un Proyecto de Ley con el Artículo 8.2.h. de la Convención Americana sobre Derechos Humanos (1991), párr. 8.

11. Art. 64.2 CADH.

12. La Expresión "Leyes" en el Artículo 30 de la Convención Americana sobre Derechos Humanos (1986), párr. 38. 
embargo, la Corte rechazó este argumento de Uruguay, pues ya había aceptado previamente resolver una solicitud de opinión consultiva sobre un proyecto de ley. En efecto, en su opinión consultiva "Propuesta de modificación” había resuelto una solicitud referida a un proyecto de reforma constitucional. Lo hizo en atención a que la competencia consultiva busca "ayudar a los Estados y órganos a cumplir y a aplicar tratados en materia de derechos humanos, sin someterlos al formalismo y al sistema de sanciones que caracteriza el proceso contencioso" ${ }^{13}$.

Sin perjuicio de lo anterior, la Corte igualmente terminó desechando la solicitud. Para hacerlo, tomó en consideración que había casos en los que la Comisión se encontraba analizando supuestas violaciones del artículo 8.2.h de la CADH, por lo que responder las preguntas de Costa Rica podría "traer como resultado una solución de manera encubierta, por la vía de la opinión consultiva, de asuntos litigiosos aún no sometidos a consideración de la Corte, sin que las víctimas tengan oportunidad en el proceso" ${ }^{14}$. Por tanto, responder la consulta podía desvirtuar la jurisdicción contenciosa y menoscabar "los derechos humanos de quienes han formulado peticiones ante la Comisión” ${ }^{15}$.

\subsection{Solicitud sobre limitaciones al nombramiento de funcionarios}

La segunda opinión consultiva que la Corte rechazó, fue resuelta el 10 de mayo de $2005^{16}$. También fue presentada por la República de Costa Rica, la que buscaba mayor claridad para resolver unos recursos de reconsideración interpuestos en contra de acuerdos que revocaban el nombramiento en propiedad de algunos funcionarios $^{17}$, basados en una norma de la Ley del Personal de la Asamblea Legislativa ${ }^{18}$. Costa Rica buscaba saber si dicha norma era compatible con los instrumentos internacionales vigentes en materia de derechos humanos ${ }^{19}$.

13. Compatibilidad de un Proyecto de Ley con el Artículo 8.2.h. de la Convención Americana sobre Derechos Humanos (1991), párrs. 15-22.

14. Coampatibilidad de un Proyecto de Ley con el Artículo 8.2.h. de la Convención Americana sobre Derechos Humanos (1991), párr. 28.

15. Op. cit., párrs. 30 y 31.

16. Solicitud de Opinión Consultiva Presentada por la República de Costa Rica (2005).

17. Op. cit., vistos párr. 2.

18. Ibid.

19. Ibid. 
Frente a esta solicitud, la Corte requirió a la Comisión Interamericana que informara si existía alguna petición individual o algún caso pendiente en contra de Costa Rica en relación con la aplicación o interpretación de las disposiciones objeto de la consulta ${ }^{20}$. La Comisión señaló que no habría ninguna relativa a dicho tema ${ }^{21}$. Sin perjuicio de ello, la Corte señaló que esta solicitud de opinión consultiva buscaba, indirectamente, dos asuntos. En primer lugar, que la Corte se pronunciara sobre un asunto que ya había sido resuelto por la Sala Constitucional de la Corte Suprema de Justicia de Costa Rica. En segundo lugar, que la Corte Interamericana se pronunciara sobre qué decisión prevalecería en una eventual contradicción entre lo dispuesto por dicha Corte Suprema y una opinión consultiva de la Corte Interamericana ${ }^{22}$. Por ello, esta última consideró que esta solicitud se refería a asuntos que, si bien no habían "sido sometidos ante el sistema interamericano dentro del mecanismo de peticiones individuales, [...] una respuesta a las preguntas de Costa Rica podría resultar en un pronunciamiento indirecto, por la vía de opinión consultiva, de asuntos litigiosos aún no resueltos a nivel interno ni sometidos a consideración de la Comisión o de la Corte" 23 . De este modo, dicha solicitud constituiría una situación que podría desvirtuar la jurisdicción contenciosa y afectar los efectos del sistema interamericano frente a los procesos pendientes en el ámbito interno ${ }^{24}$.

Es interesante notar que en esta opinión consultiva la Corte hizo un razonamiento que contiene un error lógico, en un área que es muy relevante. Dicha resolución dispuso: "la Corte ha señalado que el cumplimiento de los requisitos reglamentarios para la formulación de una consulta no implica que el Tribunal esté obligado a responderla o, contrario sensu, el incumplimiento de aquéllos no implica que la solicitud de consulta sea automáticamente inadmisible" 25 . Esta afirmación está errada, no solo porque la Corte tiene competencia para conocer de los asuntos que le encarga la CADH (y, por lo tanto, si un asunto es inadmisible según la $\mathrm{CADH}$, no tiene competencia para conocerlo), sino porque contiene un

20. Op. cit., vistos párrs. 6 y 7.

21. Ibid.

22. Op. cit., considerando párr. 12.

23. Op. cit., considerando párr. 13.

24. Ibid.

25. Op. cit., considerando párr. 5. Además, dicha afirmación tiene un error gramatical, puesto que es incorrecto el uso de la expresión "contrario sensu" en lugar de "a contrario sensu". Véase el Diccionario Panhispánico de Dudas, en http://lema.rae.es/dpd/?key=a+contrario+sensu [fecha de consulta: 25 de enero de 2017]. 
error en su uso del argumento a contrario sensu. Este argumento solo funciona con hipótesis normativas, no con meras descripciones. Además, debe tratarse de hipótesis que admitan una situación contraria, tales como "conducir sin cinturón está prohibido" - a contrario sensu "conducir con cinturón está permitido"-. Por lo demás, esta exención de la obligación de cumplir los requisitos formales no se justifica, pues en sus opiniones consultivas la Corte no está lidiando con solicitudes de personas sin recursos ni conocimientos, que difícilmente pueden cumplir con requisitos, sino que con Estados y órganos especializados, a los que se les exigen solo ciertos requisitos mínimos.

\subsection{Solicitud relativa a los condenados a muerte}

La tercera solicitud que la Corte desechó fue presentada por la Comisión Interamericana de Derechos Humanos y decidida el 24 de junio de 2005 26 . Dicha solicitud preguntaba si era congruente con las disposiciones de la CADH y de la Declaración Americana sobre los Derechos y Deberes del Hombre, el negar a los condenados a muerte el acceso a recursos judiciales o a otros recursos efectivos para impugnar dicha pena capital $^{27}$. Frente a esta solicitud, la Corte hizo presente que ella se había "referido a temas vinculados al objeto de la solicitud de opinión consultiva, que permiten conocer claramente la posición del Tribunal respecto de las preguntas formuladas por la Comisión"28. Por ello, consideró que "las respuestas a las preguntas planteadas por la Comisión [podían] extraerse del análisis e interpretación integral del corpus jurisprudencial del Tribunal" ${ }^{29}$.

Sin perjuicio de que la Corte afirmó que no se referiría a las preguntas que se le hicieron, usó tres párrafos para recordar los parámetros que ella misma había fijado en su jurisprudencia, dentro de los considerandos de esta misma resolución ${ }^{30}$. Lo hizo para probar que no era necesario darle a esta solicitud toda la tramitación que requieren las opiniones consultivas. No obstante ello, si bien no dictó una opinión consultiva, sí respondió en forma sumaria las preguntas efectuadas por la Comisión.

26. Solicitud de Opinión Consultiva Presentada por la Comisión Interamericana de Derechos Humanos (2005).

27. Op. cit., vistos párr. 1.

28. Op. cit., considerandos párr. 7.

29. Op. cit., considerandos párr. 12.

30. Op. cit., considerandos párrs. 9-11. 


\subsection{Solicitud relativa al castigo corporal}

La cuarta solicitud, resuelta el 27 de enero de 2009, también fue presentada por la Comisión Interamericana ${ }^{31}$. Ella buscaba que la Corte se refiriera a si todas las formas de castigo corporal a los niños se encontraban prohibidas, y si los Estados debían tomar medidas positivas para terminar con dicha práctica ${ }^{32}$. En este caso, la Corte también consideró que no era necesario responder a esta solicitud, en atención a que:

"las respuestas a las preguntas planteadas por la Comisión pueden extraerse del análisis e interpretación integral del corpus jurisprudencial del Tribunal sobre los derechos del niño en relación con otros criterios establecidos por éste, así como de las obligaciones emanadas por otros instrumentos internacionales, ratificados por los Estados de la región" 33 .

Como puede apreciarse, su razonamiento es similar al efectuado en la resolución sobre los condenados a muerte. No obstante, esta resolución es criticable, ya que la Corte no había dado una respuesta explícita a esta cuestión, y porque los criterios emanados de otros instrumentos internacionales no son claros. En efecto, en forma previa había señalado que los niños no podían ser objeto de malos tratos, pero esta afirmación no implicaba necesariamente afirmar que las correcciones físicas estuvieran prohibidas. El hecho de que algunas correcciones causen dolor, como puede ocurrir con un pellizco o una nalgada, no significa necesariamente que ellas constituyan un maltrato, del mismo modo en que no es un maltrato que un médico cause de forma voluntaria dolor a su paciente, para determinar el mal que sufre. En efecto, bien podría considerarse de modo legítimo que el dolor causado por una corrección es un maltrato solo si es que no cumple con la finalidad educativa o si es que causa un dolor desproporcionado. En definitiva, esta materia discutible requería que la Corte la tratara en detalle.

31. Solicitud de Opinión Consultiva Presentada por la Comisión Interamericana de Derechos Humanos (2009).

32. Op. cit., considerandos párr. 15.

33. Ibid. 
Además, tampoco estaba claro si las obligaciones contraídas por los Estados realmente prohibían los castigos corporales en el ambiente familiar. En efecto, la Corte, al referirse a esta cuestión, solo citó instrumentos que, o no hacían referencia directa a los castigos corporales, o eran solo de una naturaleza de soft law-y, por ello, no vinculantes-, como ocurre con las observaciones generales emitidas por el Comité de los Derechos del Niño.

En definitiva, si bien la Corte dijo que no respondería esta solicitud de opinión consultiva, sí la respondió, pero despachándola en forma sumaria, es decir, sin haber dado lugar al procedimiento establecido para dar respuesta a las solicitudes de opinión consultiva. Con ello, impidió que los Estados y demás interesados presentaran su opinión respecto de este tema, lo que da la impresión de que la Corte quiso responder este asunto sin exponerse a que los Estados y otros organismos mostraran que no existía una prohibición legal internacional de aplicar disciplina corporal a los niños.

\subsection{Solicitud relativa al juicio político de Dilma Rousseff}

La última solicitud de opinión consultiva rechazada, fue presentada por el Secretario General de la Organización de los Estados Americanos (OEA), quien solicitó a la Corte señalar qué criterios debían garantizarse a las autoridades nacionales a las que se hiciera un juicio político, de modo de asegurar los derechos humanos del afectado y evitar una alteración grave de los principios que rigen a todo sistema democrático ${ }^{34}$. Esta solicitud fue hecha en carácter de urgente, en relación con los hechos que estaban afectando a Dilma Rousseff, la Presidente de Brasil ${ }^{35}$. Al hacer esta solicitud, el Secretario General no cumplió con el requisito de individualizar las disposiciones de la CADH o de otros tratados sobre los que se solicitaba la interpretación, pero la Corte prefirió no rechazar esta solicitud de opinión consultiva sobre la base de tales deficiencias formales, sino que atendiendo al fondo del asunto ${ }^{36}$.

En este caso, la Corte consideró pertinente no responder esta solicitud, pues hacerlo "podría constituir un pronunciamiento prematuro sobre el tema o asunto en cuestión, el que le podría ser sometido posteriormente en el marco de un caso contencioso", y porque dar "una respuesta a la consulta planteada podría implicar

34. Op. cit., visto párr. 2.

35. Op. cit., visto párr. 4.

36. Op. cit., considerando párr. 5. Según afirmamos más atrás, nos parece que esta laxitud no es adecuada. 
pronunciarse sobre un asunto que aún no ha sido resuelto a nivel interno" 37 . Por último, notó que esta solicitud se hizo para efectos de determinar la actitud que tomaría el Secretario General respecto del artículo 20 de la Carta Democrática, pero que dicha facultad puede ser ejercida discrecionalmente, según la apreciación que el mismo Secretario General tenga respecto de si los hechos se ajustan o no a lo dispuesto en dicho artículo, por lo que consideró que no era necesario contar con la opinión de la Corte $^{38}$.

\section{Principios sentados por la Corte}

En cuanto al momento procesal para declarar la inadmisibilidad de solicitudes de consulta, la Corte lo ha hecho en dos momentos procesales distintos, antes y después de cumplir con el requisito establecido en el artículo 73.1 de su Reglamento. Tal norma exige transmitir copia de la solicitud a todos los Estados miembros, a la Comisión y a otros órganos de la OEA, para que tengan la posibilidad de presentar sus observaciones escritas ${ }^{39}$. De las cinco solicitudes de opinión consultiva rechazadas, dos lo han sido con posterioridad a la notificación y a la recepción de las referidas observaciones ${ }^{40}$.

Los principios sentados por la Corte pueden encontrarse tanto en los casos rechazados como en opiniones efectivamente contestadas. La primera opinión consultiva resuelta por ella nos legó un par de reglas generales sobre los casos en que puede rechazar referirse a una solicitud. La primera limitación a su competencia consultiva consiste en que solo puede conocer solicitudes que tengan relación con "tratados en que esté directamente implicada la protección de los derechos humanos en un Estado Miembro del sistema interamericano" (no es necesario que este haya ratificado la $\mathrm{CADH})^{41}$. Esta regla es también desarrollada en la resolución

37. Op. cit., considerando párr. 7.

38. Op. cit., considerando párr. 8.

39. Artículo 73 del Reglamento de la Corte Interamericana de Derechos Humanos. Disponible en: www.corteidh.or.cr/sitios/reglamento/nov_2009_esp.pdf, [fecha de consulta: 13 de octubre de 2016].

40. Esto ocurrió en Compatibilidad de un Proyecto de Ley con el Artículo 8.2.h. de la Convención Americana sobre Derechos Humanos (1991), párrs. 5-11 y en Solicitud de Opinión Consultiva Presentada por la Comisión Interamericana de Derechos Humanos (2005), vistos, párrs. 6-12.

41. "Otros Tratados" Objeto de la Función Consultiva de la Corte (Art. 64 Convención Americana sobre Derechos Humanos) (1982), párr. 31. 
que rechazó una solicitud de opinión consultiva en 2016, donde la afirma que la opinión consultiva debe buscar “desentrañar el sentido, propósito y razón de las normas internacionales sobre derechos humanos y, sobre todo, coadyuvar a los Estados miembros y a los órganos de la OEA para que cumplan de manera cabal y efectiva sus obligaciones internacionales" ${ }^{42}$.

Un segundo grupo de limitaciones se refiere a los casos en los que la solicitud de consulta "conduzca a desvirtuar la jurisdicción contenciosa de la Corte, o en general, a debilitar o alterar el sistema previsto por la Convención, de manera que puedan verse menoscabados los derechos de las víctimas de eventuales violaciones de los derechos humanos"43. La Corte afirma que para determinar esto, debe "considerar las circunstancias de cada caso" 44 . Estas limitaciones no parecían ser particularmente claras. Sin embargo, una resolución reciente, por la cual rechaza pronunciarse sobre la solicitud de opinión consultiva presentada en 2016 por el Secretario General de la OEA, aclaró bastante este asunto, al señalar casos en los que podría desvirtuarse su jurisdicción contenciosa. Esto ocurriría cuando una opinión consultiva:

a. Encubra un caso contencioso ${ }^{45}$;

b. Pretenda "obtener prematuramente un pronunciamiento sobre un tema o asunto que podría eventualmente ser sometido a la Corte a través de un caso contencioso" 46 o

c. Busque "obtener un pronunciamiento indirecto de un asunto en litigio o en controversia a nivel interno" $"$.

En tercer lugar, puede ser rechazada una solicitud cuando la opinión consultiva busque ser utilizada "como un instrumento de un debate político interno" 48 . Esta afirmación puede ser complementada con lo señalado en la opinión consultiva nú-

42. Solicitud de Opinión Consultiva Presentada por el Secretario General de la Organización de los Estados Americanos (2016), considerando No 6 .

43. "Otros Tratados” Objeto de la Función Consultiva de la Corte (Art. 64 Convención Americana sobre Derechos Humanos) (1982), párr. 31.

44. Ibid.

45. Solicitud de Opinión Consultiva Presentada por el Secretario General de la Organización de los Estados Americanos (2016), considerando No 6 .

46. Ibid.

47. Ibid.

48. Ibid. 
mero OC-4/84, que dispuso "[a]l decidir acerca de la admisibilidad de solicitudes de opinión consultiva sobre propuestas legislativas como tales y no sobre leyes vigentes, la Corte debe [...] actuar cuidadosamente para asegurarse de que su jurisdicción consultiva en estos casos no sea utilizada como instrumento de un debate político con el fin de afectar el resultado del proceso legislativo interno. La Corte, en otras palabras, no debe inmiscuirse en disputas políticas internas, que podrían afectar el papel que la Convención le asigna" ${ }^{49}$.

La cuarta situación que puede generar el rechazo ha sido aplicada en un par de casos reseñados, y se refiere a consultas que abarquen, “en forma exclusiva, temas sobre los que la Corte ya se ha pronunciado en su jurisprudencia" ${ }^{50}$. Además, deben rechazarse las consultas que procuren resolver cuestiones de hecho ${ }^{51}$. Por último, la competencia consultiva de la Corte "no debe, en principio, ejercerse mediante especulaciones abstractas, sin una previsible aplicación a situaciones concretas que justifiquen el interés de que se emita una opinión consultiva" ${ }^{52}$.

\section{Conclusión}

La Corte Interamericana ha sentado una jurisprudencia suficientemente abundante sobre los casos en los cuales puede declinar dar respuesta a solicitudes de opiniones consultivas. Dicha jurisprudencia requería de cierta sistematización por parte de la doctrina, pues se encuentra dispersa en las cinco resoluciones en que declinó contestar las solicitudes de opinión consultiva. A grandes rasgos, los motivos para rechazar referirse a una solicitud se reducen a los casos en que darle respuesta podría, de algún modo, resolver indirectamente un asunto contencioso que se encuentre siendo tramitado o que pudiera ser sometido al sistema; que la consulta no tenga relación con un tratado que sea aplicable en América; que el tema de la consulta ya haya sido resuelto de algún modo u otro; que, con la solicitud, se pretenda influir

49. Propuesta de Modificación a la Constitución Politica de Costa Rica Relacionada con la Naturalización (1984), párr. 30.

50. Solicitud de Opinión Consultiva Presentada por el Secretario General de la Organización de los Estados Americanos (2016), considerando № 6.

51. Ibid.

52. Titularidad de Derechos de las Personas Jurídicas en el Sistema Interamericano de Derechos Humanos (Interpretación y Alcance del Artículo 1.2, en Relación con los Artículos 1.1, 8, 11.2, 13, 16, 21, 24, 25, 29, 30, 44, 46 y 62.3 de la Convención Americana sobre Derechos Humanos, Así como del Artículo 8.1.a y b del Protocolo de San Salvador) (2016), párr. 21. 
indebidamente en el proceso democrático interno de un Estado, o que la solicitud procure solo resolver cuestiones sobre meros hechos, o referidas a especulaciones abstractas.

En una de las decisiones, la Corte afirmó que podía referirse a una solicitud de opinión consultiva, aunque el solicitante no cumpliera con los requisitos necesarios. Esta decisión no es adecuada, no solo porque el razonamiento que usó la Corte para llegar a esta conclusión fue errado, sino que también porque solo tiene competencia para actuar según lo dispuesto en la CADH. Por ello, si una de las solicitudes no cumple con los requisitos establecidos por dicho tratado, la Corte estaría actuando en exceso de poder al responderla. Por otro lado, una solicitud podría cumplir con los requisitos establecidos en la $\mathrm{CADH}$, pero no en el reglamento de la Corte. En dicho caso, también parece inapropiado que la Corte dispense de tales formalidades, puesto que su reglamento no hace excepciones, y lo propio de toda autoridad que dicta ciertas reglas, es ceñirse a ellas.

Por último, no está de más notar que la Corte debe usar cuidadosamente del rechazo de las solicitudes de opinión consultiva, puesto que dicho mecanismo podría ser inadecuadamente utilizado para evitar responder preguntas muy complejas, o para responderlas de un modo velado, evitando el procedimiento de consulta a los demás miembros de la OEA, como podría afirmarse que ocurrió en la solicitud relativa al castigo corporal de los niños.

\section{Referencias}

\section{Libros}

Burgorgue-LARSEn, Laurence y ÚBEDA DE Torres, Amaya (2011): The Inter-American Court of Human Rights. Case Law and Commentary (Oxford, Oxford University Press).

Faúndez Ledesma, Héctor (2004): El Sistema Interamericano de Protección de los Derechos Humanos: Aspectos Institucionales y Procesales (San José de Costa Rica, Instituto Interamericano de Derechos Humanos).

Hitters, Juan Carlos y Fappiano, Óscar L. (2012): Derecho Internacional de los Derechos Humanos (Buenos Aires, Ediar, 2012, Tomo II, Vol. 3).

Pasqualucci, Jo M. (2014): The Practice and Procedure of the Inter-American Court of Human Rights (Nueva York, Cambridge University Press). 


\section{Jurisprudencia citada}

"Otros Tratados" Objeto de la Función Consultiva de la Corte (Art. 64 Convención Americana sobre Derechos Humanos) (1982): Corte Interamericana de Derechos Humanos, serie A OC-1/82, 24 de septiembre de 1982, Opinión Consultiva.

Compatibilidad de un Proyecto de Ley con el Artículo 8.2.h. de la Convención Americana sobre Derechos Humanos (1991): Corte Interamericana de Derechos Humanos, serie A OC-12/91, 6 de diciembre de 1991, Opinión Consultiva.

La Expresión "Leyes" en el Artículo 30 de la Convención Americana sobre Derechos Humanos (1986): Corte Interamericana de Derechos Humanos, serie A OC-6/86. San José de Costa Rica, 9 de mayo de 1986, Opinión Consultiva.

Propuesta de Modificación a la Constitución Política de Costa Rica Relacionada con la Naturalización (1984): Corte Interamericana de Derechos Humanos, serie A OC-4/84, 19 de enero de 1984, Opinión Consultiva.

Solicitud de Opinión Consultiva Presentada por la República de Costa Rica (2005): Corte Interamericana de Derechos Humanos, 10 de mayo de 2005, Resolución de la Corte.

Solicitud de Opinión Consultiva Presentada por la Comisión Interamericana de Derechos Humanos (2005): Corte Interamericana de Derechos Humanos, 24 de junio de 2005, Resolución de la Corte.

Solicitud de Opinión Consultiva Presentada por la Comisión Interamericana de Derechos Humanos (2009): Corte Interamericana de Derechos Humanos, 27 de enero de 2009, Resolución de la Corte.

Solicitud de Opinión Consultiva Presentada por el Secretario General de la Organización de los Estados Americanos (2016): Corte Interamericana de Derechos Humanos, 23 de junio de 2016, Resolución de la Corte.

Titularidad de Derechos de las Personas Jurídicas en el Sistema Interamericano de Derechos Humanos (Interpretación y Alcance del Artículo 1.2, en Relación con los Artículos 1.1, 8, 11.2, 13, 16, 21, 24, 25, 29, 30, 44, 46 y 62.3 de la Convención Americana sobre Derechos Humanos, Así como del Artículo 8.1. a y b del Protocolo de San Salvador) (2016): Corte Interamericana de Derechos Humanos, Serie A OC-22/16, 26 de febrero de 2016, Opinión Consultiva. 